\title{
Deacidification of oils and fats of biological origine by aqueous solutions of tertiary amines*
}

Oléagineux, Corps Gras, Lipides. Volume 8, Numéro 1, 53-6, Janvier - Février 2001, Dossier : Deutsche Gesellschaft für Fettwissenschaft - Association française pour l'étude des corps gras

Auteur(s) : Siegfried PETER, Martin DRESCHER, Wolfgang KONIG, Eckhard WEIDNER, Lindenweg 3, D-91080 Uttenreuth, Germany.

Summary : Deacidification of triacylglycerols by extraction is investigated using aqueous solutions of amines as extractants. Tertiary amines with boiling points ranging between $100^{\circ}$ and $170^{\circ} \mathrm{C}$, such as 2-methylamino-diethanol, 2-dimethylamino-ethanol, 4-methylmorpholine, 1-dimethylamino-2-propanol etc. were found to be suitable substances. Especially the deacidification by aqueous solutions of 2dimethylamino-ethanol (DMAE) was amply investigated as it is used as an active agent in remedies. Amazingly gelatinous soap stocks are not formed, when the concentration of DMAE exceeds $20 \%$ if the free fatty acid content of the oil is below $15 \%$. Two liquid phases are formed in systems composed of triacylglyceroles and aqueous solutions containing 20 to 80\% DMAE. Palm oil containing 4.3 wt.\% free fatty acids was mixed with an equal amount of an aqueous solution of $30 \mathrm{wt} . \%$ DMAE at $60^{\circ} \mathrm{C}$. In equilibrium an extract containing $86 \mathrm{wt} . \%$ free fatty acids (solvents deducted) and a raffinate of 0.09 wt. $\%$ free fatty acids are obtained. Loss of neutral oil being 0.7 wt.\%.

Keywords : deacidification, extraction, amines, triacylglycerols, 2-dimethylamino-ethanol (DMAE).

\section{ARTICLE}

\section{Zusammenfassung :}

Die Abtrennung freier Fettsäuren von Triglyceriden mit Hilfe wässriger Aminlösungen wurde untersucht. Als geeignet erwiesen sich tertiäre Amine mit Siedepunkten zwischen $100{ }^{\circ} \mathrm{C}$ und $170{ }^{\circ} \mathrm{C}$, wie z.B. 2-Methylamino-diethanol, 2-Dimethylamino-ethanol, 4-Methylmorpholin und 1-Dimethylamino2-propanol. Besonders ausgiebig wurde die Entsäuerung mit wässrigen Lösungen von 2Dimethylamino-ethanol (DMAE) untersucht, da diese Substanz auch als aktive Komponente in Heilmitteln Verwendung findet. Überraschenderweise bilden sich in den untersuchten Systemen keine gelartigen Seifen bei DMAE- Konzentrationen von mehr als $20 \%$, falls die Konzentration an freien Fettsäuren im Öl geringer als $15 \%$ ist. In Systemen mit Triglyceriden und wässrigen Aminlösungen bilden sich im Bereich zwischen 20 und 80 \% DMAE zwei flüssige Phasen aus. Palmöl mit einem Gehalt von 4,3\% freier Fettsäuren wurde bei $60{ }^{\circ} \mathrm{C}$ mit der gleichen Menge einer $30 \%$ - igen DMAE Lösung versetzt. Im Gleichgewicht erhält man einen Extrakt mit $86 \%$ freier Fettsäuren und ein Raffinat mit 0,09 \% freier Fettsäuren. Der Verlust an Neutralfett beträgt nur 0,7\%.

Schlüsselbegriffe : Entsäuerung, Extraktion, Amine, Triglyceride, 2-(Dimethyl)-ethanol (DMAE).

\section{Introduction}

Crude fats and oils contain numbers of byproducts which impair storage life, smell, flavors, and appearance. The most important are suspended solids, organophosphorous compounds, free fatty acids, coloring substances, and odoriferous substances. Before deacidification slimy substances, phophatides and trace metals must be removed as completely as possible from the crude fat. When finely distributed solids and phosphorous compounds are removed further processing has the purpose 
of removing fatty acids, coloring substances, and odoriferous substances. Some vegetable oils contain commercially interesting concentrations of valuable minor components. Soy bean oil contains tocopherols, palm oil tocotrienols, tocopherols, and carotenes with concentrations between 400 and $1,000 \mathrm{ppm}$ to mention the two most important sorts of oil seeds. Recently the cultivation of oil palms and simultaneously the production of palm oil expanded rapidly and further strong growth is expected.

The commercially available crude fats and oils contain on average 1 to $5 \%$ free fatty acids (FFA), better qualities contain $0.5 \%$ and less. The free fatty acid content of refined oils and fats generally should be less than $0.1 \%$. Whereas long-chained free fatty acids mostly don't impair the flavor, the short-chained ones have soapy, rancid flavor. Under practical conditions, deacidification is mainly performed by alkali treatment or by distillation. At elevated concentrations of the alkali salts of fatty acids gelatineous soap stocks are formed [1].

At deacidification by distillation, the free fatty acids are continuously removed from the crude oils by steam stripping at vacuum. On account of the relatively elevated content of free fatty acids palm oil generally is processed by physical refining. The elevated temperatures used at physical refining (220 to $260^{\circ} \mathrm{C}$ ) destroy the carotenes and some of the tocotrienols. Owing environmental protection legislation, the process water from alkali deacidification must be processed carefully, and some expenditure is connected therewith. Therefore, physical methods for refining oils and fats have recently received increasingly attention. Since the second decade of this century the possibility of deacidification by liquid-liquid extraction using low molecular weight alkohols containing somewhat water has been discussed. Methanol was not examined comprehensively probably because of its toxicity [2].

Several industrial applications of solvent extraction by alkanols, as ethanol and 2-propanol, and furfural were proposed. These processes depend on the use of selective solvents with which the oils are not completely miscible at operating temperatures [3]. Addition of a non polar and non miscible with the extractant solvent is often realized in order to dilute the fat phase and decrease its viscosity.

Neutralizing by removing the free fatty acids using selective solvents is mainly suitable for highly acidic oils and fats. The extractant ethanol permits, e.g. the deacidification of olive oil comprising $22 \%$ free fatty acids by liquid-liquid extraction to $3 \%$ free fatty acids. The Selexol method uses liquid propane as extractant dissolving selectively saturated neutralized oils. Fatty acids, oxidation products, unsaponifiable matters and highly unsaturated glycerides are hardly dissolved and remain. The method is mainly applied for fractionation of fish oils and fish liver oils [4].

Purifying of crude glyceride oils by aqueous solutions of ammonia is proposed in the GB Patent 764,833 . The quantity of ammonia and the quantity of water are mixed with the oils in such quantities being sufficient to precipitate the gums, remove the fatty acids and separating the mixture into an oil phase and an aqueous phase containing the hydrated gums and the fatty acids [5]

E.R. Cousins et al. investigated the purifying of rice oil, which is attributed to some unknown material that tends to emulsify the oil under the conditions of chemical refining. Triethanolamine was found to effectively neutralize the emulsifying properties of the mixtures. Triethanolamine was unable to reduce the free fatty acid content to a satisfactory level in spite of the fact that it is a weak base. When both agents triethylamine and sodium hydroxide were added in an amount to that which would have been used to neutralize the free fatty acids and provide an excess of $0.4 \%$, the content of free fatty acids in refined oil was less than $1 \%$ at a refining loss between $10 \%$ to $20 \%$. Triethanolamine-deducted the refining loss amounted to $44 \%$ [6]. 
The main target of refining is decreasing the free fatty acid content on less than $0.1 \%$ at losses of neutralized oil minor than 1\%. Further aspects of interest are the recovery of valuable minor components as tocopherols, tocotrienols, sterols, and carotenes. When the production of minor components as tocotrienols and carotenes is planned, the separation of free fatty acids should be performed at moderate temperatures in order to avoid decomposition of heat sensitive substances.

\section{Materials and analysis}

Steam condensate from palm oil was applied by Cargill, The Netherlands. It's composition was: FFA $89.90 \%$, tocopherol 500ppm, tocotrienols $1,800 \mathrm{ppm}$, neutral fats + partialglycerides + unsaponifiable $9.9 \%$. The amines were supplied by Fluka a subsidiary of Sigma-Aldrich. Sunflower oil was bought from the shelf. Palm oil deacidificated was supplied by Cargill, the Netherlands. Degummed and filtered Palm oil was supplied by Daka, Lösning, Denmark. The composition of the degummed and filtered palm oil was: FFA $4.34 \%$; neutral oil $95.4 \%$; tocopherols $0.019 \%$; tocotrienols $0.073 \%$; carotenes $0.043 \%$; phytosterols $0.037 \%$.

The fat phase was analyzed by gas chromatography using a Hewlett-Packard 5890 instrument equipped with flame ionization detectors (Hewlett-Packard $\mathrm{GmbH}$, Waldbronn, Germany) on a sge12 aq2/HTS 0.1 column $\left(12 \mathrm{~m}^{\star} 0.22 \mathrm{~mm}\right.$ i.d. ${ }^{*} 0.1 \mathrm{mum}$ film). Temperature program was from $80^{\circ} \mathrm{C}(3 \mathrm{~min}$ isothermal) to $400^{\circ} \mathrm{C}, 10^{\circ} \mathrm{C} / \mathrm{min}(10 \mathrm{~min}$ isothermal). Quantitation was made using HP Chem Station Rev. 06.03. software (Hewlett-Packard). Peaks were identified by comparison with reference standards. The sample was dissolved in a mixture of heptane and pyridin in the ratio 2:1. Helium was used as carrier gas.

\section{Experimental results}

In former investigations methanol, ethanol, their mixtures with water, and poly(ethylene) glycols were proved regarding their suitability for the extraction of free fatty acids from triacylglycerols. Likewise supercritical and near-critical fluids as dimethylether, carbon dioxide, ethane, ethene, propane, propene with alcohols, acetone as entainers were investigated. Using the solvent to feed ratio1 in a four stage cross-stream extraction of abattoir fat with methanol at $60^{\circ} \mathrm{C}$ the free fatty acids (FFA) content was reduced from $1.6 \%$ to less than $0.1 \%$. Simultaneously the cholesterol content decreased from $0.25 \%$ to less than $0.1 \%$ and the fat was deodorized and decolorized. The purity of the fat met the standard [7].

Deacidification of palm oil using mixtures of carbon dioxide as supercritical extractant and dimethylether as entrainer were performed at 120 bar and $100^{\circ} \mathrm{C}$ with packings of 6 meter height. The results were suitable. With corresponding height of the packings the standard purity of free fatty acid content of less than $0.1 \%$ is available. The deacidification methods described are suitable but commercially not attractive. Therefore the extration of free fatty acids by aqueous solutions of amino compounds were investigated.

Especially tertiary amines were investigated as they do not react with free fatty acids to amides. Tertiary amines with boiling points between 100 and $170^{\circ} \mathrm{C}$ as 2-methylamino-diethanol, 4methylmorpholine, 1-dimethylamino-2-propanol, 2-dimethylamino-ethanol proved being suitable substances for the use at deacidification. 2-dimethylamino-ethanol (DMAE) is found in sea-animals as sardines and anchovies. Inside the human organism minor amounts of DMAE are found within the brain. It is known for stabilizing the cellular membranes and supports sustainably the synthesis of acetylcholine and influences positively the brain activity. Medicaments as "Ginkgo Alert Formula" and "Pedi-Active A.D.D.", for instance, contain equal amounts of DMAE and glutamine. Pedi-Active A.D.D. is prescribed for children against Attention Deficit Order/Attention Hyperactivity Deficit Disorder. 
Because of its physiologically positive properties DMAE is the preferred tertiary amine and it was investigated in greater detail regarding the deacidification of oils and fats.

Dimethylamino-ethanol is a colorless, viscos liquid. It is miscible with water and Oils and fats. When oils and fats are mixed with aqueous DMAE solutions of concentrations between $20 \%$ and $80 \%$, two liquid phases are formed. When the concentration of DMAE in the aqueous solution is below $20 \%$, high viscos aqueous phases are formed with the dissolved free fatty acids already at low loadings in the temperature region up to $80^{\circ} \mathrm{C}$.

DMAE has a boiling temperature of $135^{\circ} \mathrm{C}$ and can be separated by distillation from the fatty acids having boiling points above $200^{\circ} \mathrm{C}$, so as to yield fatty acids and solvents. The binary system of water and DMAE has an azeotropic point at $93^{\circ} \mathrm{C}$ and ambient pressure. The azeotrope consists of $10 \%$ DMAE and $90 \%$ water. A small amount of DMAE (about 0.5 to $2 \%$ depending on the concentration) is dissolved in the deacidified oil. It can be removed by water wash or by steam stripping for instance in connection with deodorization as DMAE is very volatile in steam.

The solubility of fatty acids in aqueous solutions of DMAE depend on temperature and concentration. In Figure 1 the solubility of oleic acid is plotted as function of the dimethylamino-ethanol concentration of the aqueous solution at $50^{\circ} \mathrm{C}, 60^{\circ} \mathrm{C}, 80^{\circ} \mathrm{C}$, and $90^{\circ} \mathrm{C}$. The solubility of oleic acid increases with increasing DMAE content and increasing temperature.

Refining the oil with aqueous solutions of DMAE will remove the free fatty acids with substantially no saponification loss. By subjecting the aqueous phase to distillation, the extractant composed of water and DMAE is distilled out and recovered for re-use, with direct production of free fatty acids and no net consumption of the reagent in the process.

At fatty acid concentrations beyond $25 \%$ the aqueous solutions of DMAE become increasingly gelatinous with increasing concentration at temperatures below $80^{\circ} \mathrm{C}$. Generally, the concentration in question is not attained in equilibrium with crude oils and fats. The oil phase as well as the extract phase are in liquid state. When the deacidification of a product with high concentrations of free fatty acids like damper condensate (about 80 to 90\%) is proposed, the fatty acid concentration of the aqueous DMAE solution exceeds the limit of $25 \%$. When this holds true, the process temperature has to be increased beyond $80^{\circ} \mathrm{C}$ in order to obtain liquid extract phases.

With increasing water content the selectivity increases and the solubility of triacylglycerols decreases. For minimizing the loss of neutralized fat the water content of the extractant should be great. Practically aqueous solutions of $30 \%$ DMAE are selective extractants yielding refining losses of neutralized oil less than $1 \%$. In order to produce fat losses less than $1 \%$ the concentration of free fatty acids of the extracted material must increase to values above $80 \%$. In Figure 2 the loss of neutral oil is plotted as function of the FFA content of the extract.

The extracted free fatty acids are separated from the extractant by distillation. First a mixture of water and DMAE is vaporized and subsequently DMAE. Due to its high steam volatility slight residues of DMAE can be easily removed completely by steam stripping. Only very slight residues of DMAE remain in the oil phase. These are removed by steam stripping in the course of deodorisation as well. No waste water containing salts and/or minor residues of soap is produced by the process proposed. 


\section{Continuous deacidification}

Deacidification of palm oil by continuous extraction with an aqueous solution of DMAE was investigated using a rotating disc contactor. In Figure 3 a schematic flow sheet is shown of the experimental device consisting of a rotating disc contactor, two vessles containing oil and extractant respectively, and two further vessels for the products. The degummed and filtrated palm oil was processed at $80^{\circ} \mathrm{C}$ in countercurrent flow with an extractant composed of $40 \mathrm{wt} . \%$ DMAE and $60 \mathrm{wt} . \%$ water. The cross-section load amounted to $5 \mathrm{~m}^{3} / \mathrm{m}^{2} / \mathrm{min}$. The solvent to feed ratio amounted to 1 . The composition of feed, extract, and raffinate (solvent deducted) obtained is shown in Table 1.

Condensate by steam stripping of palm oil obtained in physical refining is dissolved in the twofold amount of hexane in order to produce a two phase system, when mixed with an extractant composed of $40 \%$ water and $60 \%$ DMAE. For example, $200 \mathrm{~g}$ condensate were dissolved in $400 \mathrm{~g}$ hexane. This solution was mixed by stirring with a solution composed of $360 \mathrm{~g}$ DMAE and $240 \mathrm{~g}$ water at $80^{\circ} \mathrm{C}$. After interruption of stirring two phases separated within 5 minutes. In Table 2 the composition of the two phases obtained (solvent deducted) is shown.

In Table 3 the results of the extraction with an aqueous solution of $30 \%$ DMAE at $50^{\circ} \mathrm{C}$ with damper condensate at a solvent to feed ratio of 1:2 are shown.

The products are a deacidified oil free of soap residues and fatty acids free of alkali salts. No waste water with dissolved salts is formed.

\section{Discussion}

Deacidification by aqueous alkali solutions results from the formation of alkali salts of the fatty acids. By neutralisation with acids, preferably sulfuric acid, the fatty acids are separated from the aqueous solution. The aqueous solution of alkali salts formed has to be removed as a waste. Whereas the fatty acids dissolved in aqueous solutions of tertiary amines can be worked up by distillation, and the formation of waste water is avoided.

When the boiling point of the amine is above the boiling point of water, the water is removed first and the formation of a gelatinous soap stock at low amine concentrations is avoided. Water and amines are removed as distillate and the fatty acids are obtained as bottom product. When the vapor pressure of the amine would be greater than the vapor pressure of water the amine concentration of the extract decreases and at low amine concentrations a soap stock would be formed.

When the deacidification of palm oil by extraction with aqueous solutions of DMAE is performed at temperatures below $100^{\circ} \mathrm{C}$ temperature sensitive minor components as carotenes, and tocotrienols are not damaged. First the degummed and filtrated palm oil is winterized at about $-5^{\circ} \mathrm{C}$. The cristallized material is separated by centrifugation or filtration. Thus the melting point of the winterized oil is reduced to about 5 to $10^{\circ} \mathrm{C}$. Subsequently the filtrate is deacidified by extraction with an aqueous solution of $30 \%$ DMAE. The content of free fatty acids is reduced to about $0.05 \%$. Residues of DMEA in the deacidified oil are removed by water wash. The palm oil processed contains the minor components in slightly increased concentrations. Thus a marketable product for daily use can be obtained. The tasty oil contains the minor components as carotenes, tocotrienols, tocopherols, and phytosterols in unimpaired quality. The oil produced in this way has health promoting attributes. 


\section{CONCLUSION}

Deacidification of oils and fats using aqueous solutions of amines as extractants is practicable. Suitable basic compounds for the extraction process should have the following properties: a) the compound should not form amides with the free fatty acids; b) the compound should be miscible with water in any proportion; c) the boiling temperature should be equal or greater than the boiling temperatur of water; $d$ ) the molestation by smell should be as slight as possible. A prefered compound is 2-dimethylamino-ethanol standing out for medical grounds.

Refining the oil using aqueous solutions of DMAE as an extractant will remove the free fatty acids with substancially no loss of neutral oil. By subjecting the aqueous phase to distillation the extractant composed of water and DMAE is distilled out and recovered for re-use, with direct production of free fatty acids. No net consumption of the reagent occurs. No waste water is produced. Due to the moderate process temperatures heat sensitive substances, as carotenes or tocotrienols for instance, are not decomposed.

\section{Acknowledgement}

The authors thank Bjarne Holm-Jensen and Poul Möller for valuable discussions. Special thanks to Daka a.m.b.a., Lösning, Denmark for the financial assistance to allow this research to be carried out.

* Extended version of the lecture presented on the Joint International Congress and Expo Würzburg, Germany, October 8-10, 2000.

\section{REFERENCES}

1. HUI YH, ed. Refining and Bleaching. Bailey's Industrial Oil \& Fat Products. Fifth Edition, vol. 4. New York: John Wiley \& Sons Inc, 1996: 172-88.

2. BERNARDINI E (1985). Deacidification with Isopropanol. Oilseeds and Fats, Publishing House Rom.

3. US Patent 2,200,391 (S.E. Freeman, 14. May 1940). Solvent Extraction of Glyceride Oils.

4. PASSIMO HJ (1949). Refining using Liquid Propane (Selexol-Process). Ind Eng Chem, 41: 280-7.

5. GB Patent 764833 (B. Clayton, 2.Jan. 1954). Improvements in or relating to Treatment of Glyceride Oils.

6. COUSINS ER, PRACHANKADEE R, BHODIPRASART S (1955). Ethanolamines and other Aminoand Hydroxyl- Containing Compounds in the Refining of Rice Oil. JAOCS, 32: 561-4.

7. DRESCHER M, PETER S, WEIDNER E (1999). Investigations on Physical Refining of Animal Fats and Vegetable Oils. Fett/Lipid, 101: 138-41. 
Illustrations

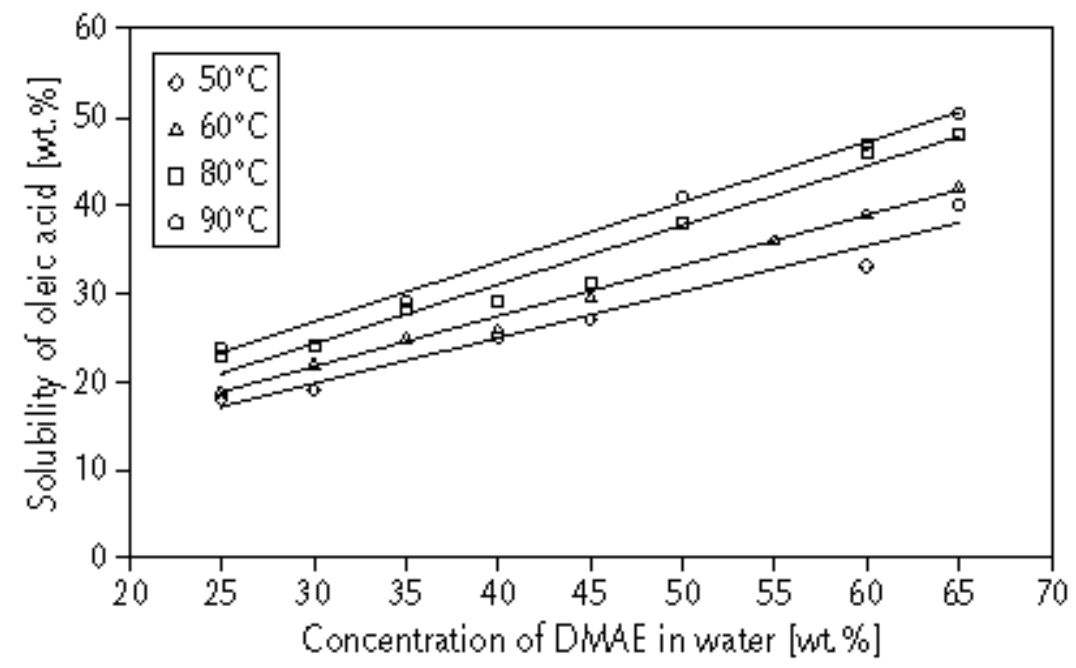

Figure 1. Solubility of oleic acid as function of the concentration of 2-dimethylamino-ethanol at various temperatures.

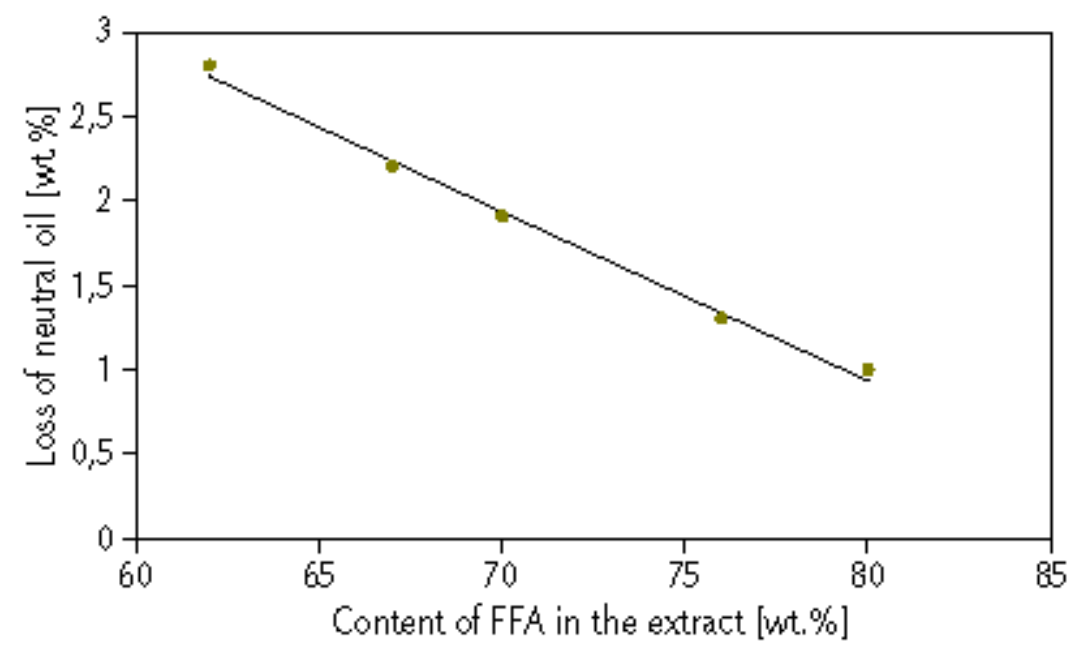

Figure 2. Loss of neutral oil versus concentration of free fatty acids in the extract. 


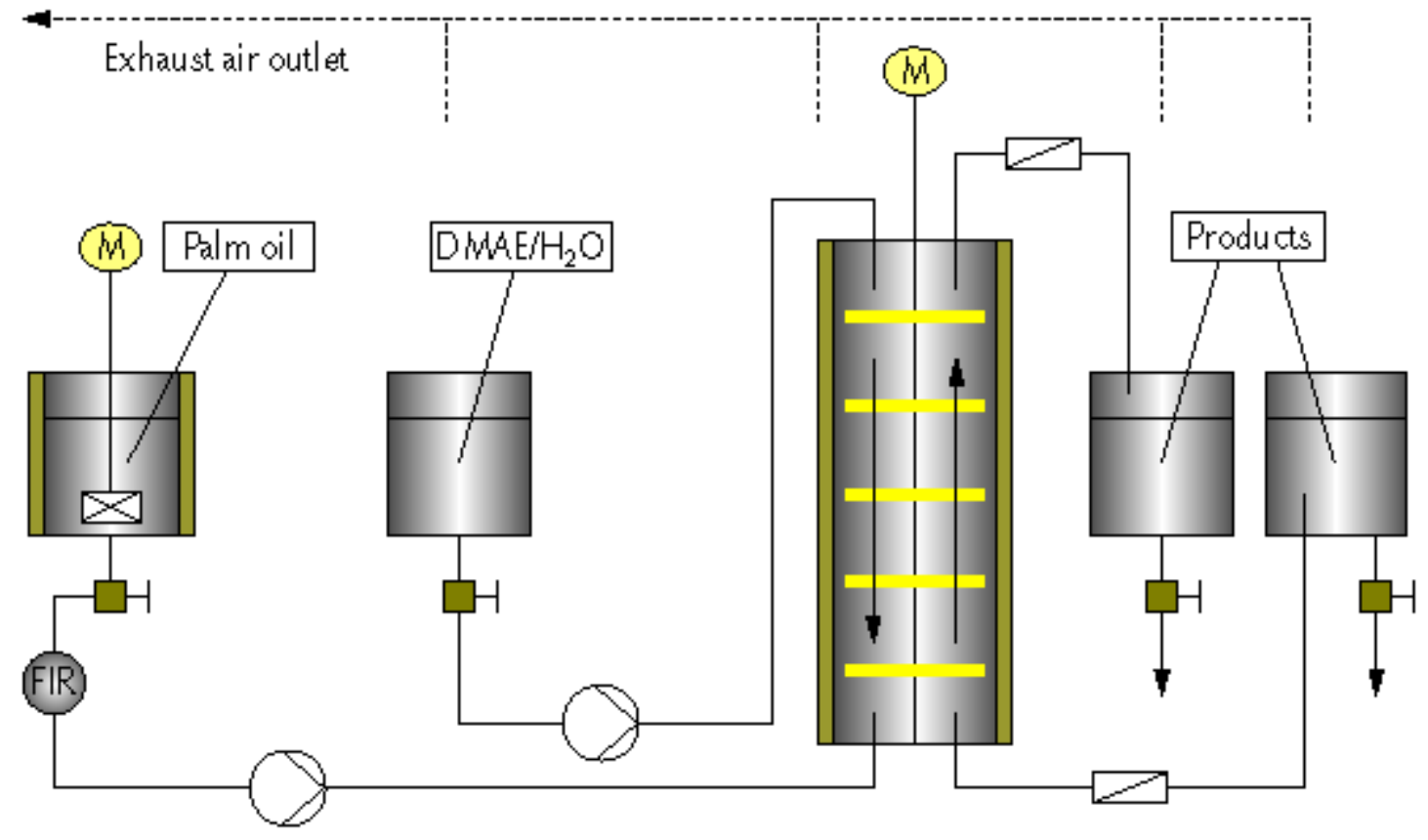

Figure 3. Schematic flow sheet of the experimental device for countercurrent extraction.

Table 1. Deacidification of palm oil by extraction with an aqueous solution of $40 \mathrm{wt} \%$ DMAE at $80^{\circ} \mathrm{C}$.

\begin{tabular}{l|c|c|c|c|c|c} 
& $\begin{array}{c}\text { Neutral oil } \\
\text { [wt.\%] }\end{array}$ & $\begin{array}{c}\text { FFA } \\
\text { [wt.\%] }\end{array}$ & $\begin{array}{c}\text { Tocopherols } \\
\text { [wt.\%] }\end{array}$ & $\begin{array}{c}\text { Tocotrienols } \\
\text { [wt.\%] }\end{array}$ & $\begin{array}{c}\text { Phytoste rols } \\
\text { [wt.\%] }\end{array}$ & $\begin{array}{c}\text { Carotenes } \\
\text { [p pm] }\end{array}$ \\
\hline Feed & 95.52 & 4.34 & 0.02 & 0.07 & 0.05 & 430 \\
Extract & 23.77 & 75.98 & 0.04 & 0.09 & 0.07 & 400 \\
Raffinate & 99.74 & 0.10 & 0.02 & 0.07 & 0.04 & 410
\end{tabular}

Table 2. Extraction of a 1:2 mixture of palm oil damper condensate and hexane with an aqueous solution of 60 wt. $\%$ DMAE at $80^{\circ} \mathrm{C}$.

\begin{tabular}{l|c|c|c} 
& $\begin{array}{c}\text { Neutral oil } \\
\text { [wt.\%] }\end{array}$ & $\begin{array}{c}\text { FFA } \\
\text { [wt.\%] }\end{array}$ & $\begin{array}{l}\text { Tocols } \\
\text { [wt.\%] }\end{array}$ \\
\hline Feed & 13.6 & 86.0 & 0.4 \\
Lower Phase & 7.0 & 92.6 & 0.3 \\
Upper Phase & 97.7 & 0.3 & 2.0
\end{tabular}


Table 3. Extraction of palm oil damper condensate with an aqueous solution of $30 \mathrm{wt} \%$ DMAE at $50^{\circ} \mathrm{C}$.

\begin{tabular}{l|c|c|c|c} 
& $\begin{array}{c}\text { Triglycerides } \\
\text { [wt.\%] }\end{array}$ & $\begin{array}{c}\text { Diglycerides } \\
\text { [wt.\%] }\end{array}$ & $\begin{array}{c}\text { Monoglycerides } \\
\text { [wt.\%] }\end{array}$ & $\begin{array}{c}\text { FFA } \\
\text { [wt.\%] }\end{array}$ \\
\hline Lower Phase & 1.8 & 4.1 & 5.9 & 88.3 \\
Upper Phase & 83.9 & 13.5 & 0.2 & 2.4
\end{tabular}

